\title{
Implementation of Behavioral Therapy (Economic Token) on the Ability of People with Mental Disorders in Fulfilling Self-Cleaning (Personal Hygiene) in Medan Sunggal Subdistrict
}

\author{
Mahnum Lailan Nasution*(D), Wardiyah Daulay (D), Sri Eka Wahyuni(D) \\ Department of Psychiatric Nursing, Faculty of Nursing, University of Sumatera Utara, Medan, Indonesia
}

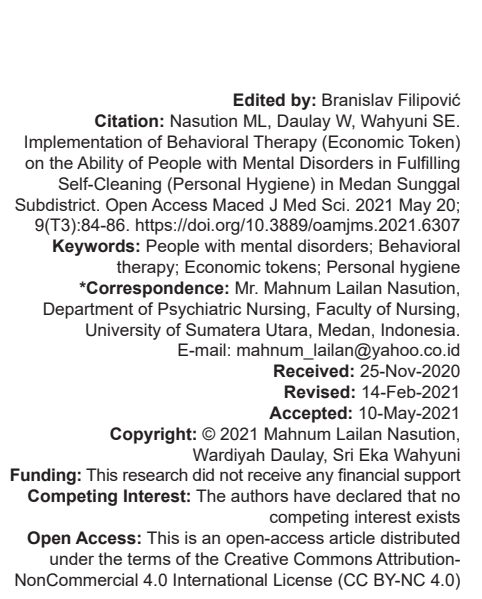

Abstract

BACKGROUND: Some common problems experienced by all people with mental disorders (ODGJ) are impaired personal hygiene activities including bathing, dressing up, eating, and toileting. Psychiatric nurses must, therefore, possess the ability and knowledge on how to meet the personal hygiene requirements for these patients by providing caregiving with behavioral therapy (economic tokens), through behavior modification, using positive reinforcement.

AIM: This study aimed to apply behavioral therapy (economic tokens) to the ability of ODGJ in the fulfillment of personal hygiene within Medan Sunggal subdistrict.

MATERIALS AND METHODS: The research type used was quasi-experiment with the one-group pre-test-posttest approach, while the procedure was performed by providing nursing actions in the form of behavioral therapy (economic tokens). This study involved a total of 31 respondents with mental disorders ODGJ, obtained through total sampling in the unified Medan Sunggal subdistrict.

RESULTS: The use of behavioral therapy (economic tokens) was found to improve the ability of ODGJ to carry out personal hygiene, with a mean difference of 1.19 (from 1.87 to 3.06 )

CONCLUSIONS: Psychiatric nurses, therefore, ought to motivate and help accompany families to monitor the personal hygiene fulfillment ability of family members with mental disorders.

\section{Introduction}

Mental health care is required by all individuals and is not just limited to mental disorders. According to Purwanto [1], mental well-being remains a significant problem around the world, including Indonesia. In addition, the basic health research [2] conducted by the Ministry of Health, Republic of Indonesia reported an increase in the prevalence of households with severe mental disorders (schizophrenia or psychosis) in North Sumatra Province, $0.09 \%$ in 2013 , to $0.6 \%$ in 2018 . Daily personal hygiene is crucial, influences well-being, and is strongly influenced by individual values as well as habits [3]. However, the inability to fulfill personal hygiene is a major problem (negative symptom) faced by people with mental disorders (ODGJ). This is a condition where the individual experiences a damage to motor or cognitive function, leading to a decrease in the ability to perform self-care activities.

\section{Behavioral therapy}

Total $(100 \%)$ lack of self-care is a problem often encountered in nursing. In ODGJ, this challenge is due to changes in thought processes leading to a decline in personal hygiene activities. Hence, psychiatric nurses play an important role in handling the self-care problems faced by these individuals, as personal hygiene requirements must be met to maintain cleanliness as well as for physical and psychological well-being [4]. The inability to perform activities including bathing, eating, drinking, and dressing up independently, as well as toileting [5] observed in ODGJ therefore requires correction through behavioral therapy. This can be carried out with the token economy behavior modification procedure using positive reinforcement, where one piece (signal/sign) is given as soon as possible, each time the target behavior appears.

The economic token therapy is designed to increase desirable behavior and reduce unwanted behavior [1]. In addition, applying behavioral therapy (economic tokens) to maximize the fulfillment of personal hygiene in ODGJ tends to reduce daily care dependence and optimize mental health care in the community.

\section{Materials and Methods}

This activity was implemented in several steps. The first stage of the pre-test was handing out 
personal hygiene questionnaires to ODGJ, while the second involved economic token behavior therapy. This implementation was carried out in six sessions at intervals of 1 day. Furthermore, each session was 30 min long and utilized tokens (Coins), clarity defining behavior, back-up reinforces, token exchange systems, data recorders, and implementation of economic token consistency. Subsequently, the third phase (post-test) was carried.

\section{Results}

Table 1: Demographic characteristics by age of ODGJ in the Medan Sunggal subdistrict $(n=31$ people)

\begin{tabular}{llll}
\hline Age mean & Minimum & Maximum & SD \\
\hline 38 tahun & 17 & 81 & 12.870 \\
\hline
\end{tabular}

Table 1 shows the demographic characteristics. The respondents involved in this study were all ODGJ in the Medan Sunggal subdistrict area. According to the demographic data, the average age of ODGJ was 38 years, while the lowest and highest ages were 17-81 years, respectively. In addition, out of the respondents, $71 \%$ were male, and $84 \%$ were diagnosed with schizophrenia (Table 2).

Table 2: Demographic characteristics of ODGJ in the Medan Sunggal subdistrict $(\mathrm{n}=31$ people)

\begin{tabular}{lll}
\hline Characteristics & Frequency & Percentage \\
\hline Sex & & \\
Male & 22 & 71 \\
Female & 9 & 29 \\
Medical diagnose & & \\
$\quad$ Schizophrenia & 26 & 84 \\
Depression & 3 & 10 \\
Anxiety & 1 & 3 \\
$\quad$ Others & 1 & 3 \\
\hline Demographic characteristics of people with mental illness in Medan Sunggal subdistrict $(\mathrm{n}=31)$
\end{tabular}

The data obtained were processed using dependent t-test, to ascertain the effectiveness of applying behavioral therapy. Table 3 shows the results obtained, including $p=0.00$.

Table 3: Fulfillment of personal hygiene, before and after behavioral therapy (economic tokens) on the ability of people with mental disorders in Medan Sunggal subdistrict

\begin{tabular}{lllll}
\hline Fulfillment of personal hygiene ODGJ & Mean & SD & SE & p-value \\
\hline Before behavioral therapy & 1.87 & 0.763 & 137 & 0.00 \\
After behavioral therapy & 3.06 & 0.629 & 113 & \\
Mean difference & 1.19 & & & \\
\hline Fulfillment of personal hygiene, before and after behavioral therapy (economic tokens) on the ability of
\end{tabular}

ODGJ in Medan Sunggal subdistrict $(n=31)$. ODGJ: People with mental disorders.

\section{Discussion}

Based on the results of this study, the implementation of behavioral therapy (economic tokens) improved the personal hygiene fulfillment ability of ODGJ in Medan Sunggal subdistrict from 1.87 to 3.06. This means a mean difference of 1.19 in the behavioral changes was attained.

According to the initial survey performed by researchers, self-care deficit is a disorder leading to inability to perform self-care activities including bathing, decorating, toileting, and eating. This tends to lead to skin problems, disruption of the oral mucous membrane, abnormalities in the nails, and also impact the patient's psychology as well as transmit several diseases to people in close proximity. Personal hygiene maintenance is the act of maintaining self-cleanliness and health for physical and psychological well-being. Thus, a person is said to have good personal hygiene when the cleanliness of one's body including the skin, teeth and mouth, hair, eyes, nose, ears, feet, nails, genital, as well as the neatness of the clothes [6], is properly maintained.

The self-care requirements for ODGJ are increased due to the disorders in cognitive, assertive, and psychomotor aspects [7]. However, these individuals tend to practice self-care when turned into a daily routine. Psychiatric patients with structured activities have a greater success rate compared to patients without [8]. Therefore, the ODGJ, initially unable to perform self-care because of ignorance, unwillingness, and inability, exhibited behavioral changes as these patients currently know, desire, and are able to carry out scheduled self-care.

Several behavioral modification therapies exist for patients with self-care deficit disorder, including the economic token technique [9]. An economic token is a formal description of an antecedent (stimulus) relationship, behavior and consequences, designed to modify or influence behavior by increasing desired, and reducing unwanted behavior through positive reinforcement. The collected tokens are then exchanged for prizes (reinforces), based on quantity.

This technique has been found to positively influence personal hygiene activities in self-care deficit patients. These improvements occurred after rewards and praises were given for performing personal hygiene activities. Hence, praising and rewarding patients with mental disorders motivate self-care and increase happiness [10].

In addition, economic token techniques are more effective in improving personal hygiene activities and lead to long-lasting reinforcement because the token is given as soon as a desired behavior appears, and afterward, exchanged for reward [11]. Therefore, these methods are suggested for improving the behavior of patients with personal hygiene problems, particularly the in-house counterparts [12]. This is in accordance with the previously postulated theory stating the positive influence of economic token technique for patients with impaired personal hygiene activities [13].

The patients were said to exhibit improved personal hygiene after the economic token method 
was conducted, due to the provision of effective reinforcement by awarding an asterisk $\left({ }^{*}\right)$ as the token, for the purpose of this study. Furthermore, as more asterisks are obtained, the patient becomes happy and proud to have attained the star sign and consequently, possesses increased confidence in the personal hygiene abilities possessed. In addition to this, the patient is also rewarded after successfully doing personal hygiene activities.

The theory is, therefore, in accordance with the improvement observed from the research conducted on the influence of token economy methods on personal hygiene activities in self-care deficit patients at Professor HB Sa'anin Mental Hospital, Padang. The rewards given to the patients were toiletries, and [14] this fostered the patient's motivation to perform personal hygiene activities. Meanwhile, a study conducted by Suardika (2012), titled "Effect of Economic Token Therapy on Ability to Control Violent Behavior in Mental Disorders Clients in Bali Provincial Mental Hospital," also reported differences and after economic token therapy implementation.

\section{Conclusions}

The results showed the influence of behavioral therapy (economic tokens), on the ability of ODGJ in carrying out personal hygiene, in Medan Sunggal subdistrict.

\section{Recommendation}

Psychiatric nurses, therefore, ought to assist and motivate families to monitor the ability to fulfill personal hygiene of family members with mental disorders. Furthermore, the community health service (Puskesmas) ought to send mental health workers on continuous home visitation programs with regard to personal hygiene fulfillment in patients and collaborates with educational institutions to improve mental health programs in the community.

\section{References}

1. Purwanto T. Textbook of Mental Health Nursing. Yogyakarta: Pustaka Pelajar; 2015

2. Ministry of Health Republic of Indonesia. Basic Health Research; 2018. Available from: https://www.kemkes.go.id/resources/ download/info-terkini/hasil-riskesdas-2018.pdf.

3. Hidayat A. Introduction to Basic Human Needs. Jakarta: Salemba Medika; 2009.

4. Afnuhazi R. Therapeutic Communication in Mental Health Nursing. Yogyakarta:2015.

5. Abdul NM. Dasar-Dasar Keperawatan Jiwa Pengantar Dan Teori. Jakarta: Salemba Medika; 2015.

6. Arif A. Nursing Care of Patients with Neurological Disorders. Jakarta: EGC; 2008.

7. Susanti H. Self-care deficits in schizophrenic patients: Application of Orem's self care theory. Indones Nurs J. 2015;13:87-97

8. Videbeck SL. Textbook of Mental Health Nursing. Jakarta: EGC; 2008.

9. Fisher WW, Piazza CC, Roane HS. Functional analysis: History and methods. In: Handbook of Applied Behavior Analysis. New York: Guilford Press; 2011.

10. Iyus Y. Mental Health Nursing. Bandung: Refika Aditama; 2009

11. Sulizah B. Holistic Approach to Mental Disorders. Jakarta: FKUI; 2007.

12. Kaplan S. Synopsis of Psychiatry. Vol. 2. Jakarta: EGC; 2007.

13. Sugianti S. Mental Health Not Getting Enough Attention; 2008. Available from: https://syehaceh.wordpress.com/. [Last accessed 08 Jul 2020].

14. Sasmita $H$, Mahdairta $R$, Asterina A. The effect of the token economy method on self-care activities in patients with self-care deficits. Nurs J. 2012;8(1):23-30. 